\title{
Indirect measurements of sweat electrolyte concentration in the laboratory diagnosis of cystic fibrosis
}

\author{
Mary E Heeley, David A Woolf, Anthony F Heeley
}

\begin{abstract}
Aim-To investigate whether analytical methods based on the colligative physical chemical properties of ions or solutes in sweat are less effective than the specific measurement of electrolytes in the diagnosis of cystic fibrosis (CF).

Methods-A single sweat sample was collected (Macroduct) from each of 211 infants and children, of whom 57 had CF, for the measurment of sodium, chloride, osmolality, and conductivity.

Results-The ranges within which $\mathrm{CF}$ and non-CF individual values overlapped (equivocal ranges), were wider for sodium and osmolality measurement than for chloride or conductivity. Neither of the latter two measurements provided a discriminatory advantage over the other. The utilisation of broadly based age related ranges for non-CF control subjects served to improve the discriminatory power of all four measurements to an extent that, in this cohort, both chloride and conductivity provided complete discrimination.

Conclusion-Sweat conductivity is as effective as chloride measurement in the laboratory diagnosis of CF.

(Arch Dis Child 2000;82:420-424)
\end{abstract}

Keywords: cystic fibrosis; sweat test; sodium; chloride; conductivity; osmolality

The laboratory diagnosis of cystic fibrosis (CF) remains largely dependent on the measurement of electrolytes in sweat, despite the clear benefits that CFTR mutation analysis has brought to the diagnostic process. ${ }^{1}$ In the USA the sweat test is one of those clinical laboratory procedures for which National Consensus Guidelines have been issued as an aid to good practice. ${ }^{2}$ The latter include advice that indirect physical chemical measurements, osmolality, and conductivity, provide only approximate estimates of sweat electrolyte concentration, to a degree that renders them unreliable for the purpose of diagnostic testing. This view has been endorsed by the American CF Foundation with the recommendation that the "indirect" methods should be confined to use as screening tests. ${ }^{12}$ In the absence of supporting laboratory data it is necessary to question the validity of such advice and recommendations.

In this study we have sought to obtain comparative data from these different methods of measurement. We consider that the issue is one of importance for clinical, and in particular,
Table 1 Number (\%) of control subjects according to clinical category

\begin{tabular}{lll}
\hline & \multicolumn{2}{l}{ Control subjects } \\
\cline { 2 - 3 } Signs and symptoms & $n$ & $\%$ \\
\hline Failure to thrive + GI obstruction, & & \\
$\quad$ diarrhoea, rectal prolapse & 70 & 45 \\
Respiratory & 46 & 30 \\
Failure to thrive + respiratory & 20 & 13 \\
Family history of CF (well) & 9 & 6 \\
Positive screening test (well) & 5 & 3 \\
Prolonged jaundice & 2 & 1.5 \\
Failure to thrive + family history & 2 & 1.5 \\
\hline
\end{tabular}

paediatric practice, not only because these recommendations are becoming more widely publicised, ${ }^{3}$ but also because in the UK, to our knowledge, a considerable number of hospital laboratories are using indirect methods to provide sweat test results for diagnostic purposes.

\section{Subjects and methods}

Sweat tests were carried out on 57 infants and children with CF (mean age 3 years 10 months, range 0.5 months to 15 years), and on 154 who did not have this disease and who served as controls (mean age 2 years 10 months, range 0.5 months to 14 years 8 months). The latter were mostly infants and children, under the clinical care of one of us (DAW), who had presented with one or more of the signs and symptoms commonly associated with CF. In view of the fact that virtually all (98\%) CF cases born in East Anglia are detected by neonatal screening, and that most control subjects had been screened with negative results, a diagnosis of $\mathrm{CF}$ was considered unlikely in the vast majority of these cases. However, in a nonscreening setting, it was considered that sweat testing would have been justified. A small minority of control subjects were well infants who underwent sweat testing either on the grounds of an existing family history of the disease or because of a positive neonatal screening test result (prolonged neonatal hypertrypsinaemia), but who on clinical examination were found to have no discernible signs or symptoms; the sweat test results obtained were not considered diagnostic for CF by the generally accepted criteria, as defined below in Results. Table 1 shows the proportion of control subjects in these various clinical categories.

The CF patients included those, who during the period of this study, had positive screening test results; diagnostic sweat tests were therefore performed. In most of these cases diagnosis was confirmed by mutation detection and, in the course of time, most infants developed some of the clinical signs and symptoms of the 
Table 2 Results of direct and indirect electrolyte measurement in sweat, including equivocal ranges and number of subjects contributing to them

\begin{tabular}{|c|c|c|c|c|c|c|c|c|}
\hline & \multicolumn{2}{|c|}{$\begin{array}{l}\text { Conductivity } \\
(\text { mmol }(\mathrm{NaCl} \text { eq)/l) }\end{array}$} & \multicolumn{2}{|c|}{ Osmolality ( $\mathrm{mmol} / \mathrm{kg})$} & \multicolumn{2}{|c|}{ Sodium $(\mathrm{mmol} / \mathrm{l})$} & \multicolumn{2}{|c|}{ Chloride (mmol/l) } \\
\hline & Control & $C F$ & Control & $C F$ & Control & $C F$ & Control & $C F$ \\
\hline Mean (SD) & $37(10)$ & $110(13)$ & $101(25)$ & $237(25)$ & $23(12)$ & $88(15)$ & $14(8)$ & 99 (18) \\
\hline Observed range & $18-71$ & $67-141$ & $66-172$ & $157-278$ & $4-66$ & $36-117$ & $4-47$ & $46-123$ \\
\hline Range: $\mathrm{CF}_{\min }-$ control $_{\max }$ & \multicolumn{2}{|c|}{$67-71$} & \multicolumn{2}{|c|}{$157-172$} & \multicolumn{2}{|c|}{$36-66$} & \multicolumn{2}{|r|}{$46-47$} \\
\hline Total no. subjects & \multirow{2}{*}{\multicolumn{2}{|c|}{3}} & \multicolumn{2}{|c|}{7} & \multicolumn{2}{|c|}{12} & \multicolumn{2}{|r|}{2} \\
\hline $\mathrm{CF}(\mathrm{n})^{\star}$ & & & & & \multirow{2}{*}{\multicolumn{2}{|c|}{$\begin{array}{c}4(\mathrm{~A}, \mathrm{~B}, \mathrm{C}, \mathrm{D}) \\
8(\mathrm{E}, \mathrm{F}, \mathrm{H}, \mathrm{I}, \mathrm{J}, \mathrm{K}, \mathrm{L}, \mathrm{N})\end{array}$}} & & $1(\mathrm{~B})$ \\
\hline Control $(\mathrm{n})^{\star}$ & \multicolumn{2}{|c|}{$2(\mathrm{E}, \mathrm{G})$} & \multicolumn{2}{|c|}{$6(\mathrm{E}, \mathrm{F}, \mathrm{G}, \mathrm{H}, \mathrm{L}, \mathrm{M})$} & & & \multicolumn{2}{|r|}{$1(\mathrm{G})$} \\
\hline
\end{tabular}

${ }^{\star}$ Individual patients $\mathrm{A}-\mathrm{N}$, in parentheses, as referred to in text.

condition. Sweat tests in older infants and children were undertaken when attending routine outpatient appointments; informed consent to repeat the test had been obtained from the parent or, when appropriate, the child.

The Regional Ethical Committee approved the protocol for this study. There was no prior selection of patients for entry into this study either on grounds of clinical severity or genotype. However, the aim was to have, for both CF and controls, a similar population sample with age range from birth to 15 years and a mean/median in the range $2-4$ years, on the grounds that this would not be too dissimilar to the timescale generally experienced to achieve clinical diagnosis of the condition in an unscreened population.

From each patient and control subject a single sweat sample was collected using the Macroduct 3700 sweat collection system (Wescor Inc., Logan, Utah, USA), as described previously, ${ }^{4}$ and in accordance with the manufacturer's instructions. This provided a mean sweat production rate of $2 \mu \mathrm{l} / \mathrm{min}$ during a mean collection period of 24 minutes (maximum 35 minutes), minimum sweat volume requirement $22 \mu \mathrm{l}$ for all measurements described below. During this study we failed to obtain the minimum amount of sweat at the first attempt in only three patients $(1.4 \%)$.

The following measurements were made in each sweat specimen: sodium by flame photometry, chloride colorimetrically, ${ }^{5}$ and osmolality and conductivity by the Model 5200 vapour pressure osmometer and the Sweat Check Conductivity Meter (Wescor Inc., Logan, Utah, USA) in accordance with the manufacturer's instructions and as described previously. ${ }^{4}{ }^{6}$ Between assay $(n=30)$ coefficients of variation, at critical values for these four measurements, were: conductivity $1.0 \%$ at $67 \mathrm{mmol}(\mathrm{NaCl}$ eq) $/ 1$, osmolality $2.9 \%$ at 127 $\mathrm{mmol} / \mathrm{kg}$, sodium $4.3 \%$ at $53 \mathrm{mmol} / \mathrm{l}$, and chloride $2.5 \%$ at $50 \mathrm{mmol} / 1$.

Sweat osmolality and sodium only were measured in a further 74 control infants and 58 infants with CF under the age of 12 weeks; these results are presented separately.

Table 3 "Equivocal" results obtained in sweat of four $C F$ patients

\begin{tabular}{lllllll}
\hline Patient & $\begin{array}{l}\text { Age } \\
(\text { mth })\end{array}$ & Genotype & $\begin{array}{l}\text { Conductivity } \\
(\text { NaCl eq) } / l)\end{array}$ & $\begin{array}{l}\text { Omolality } \\
(\text { mmol/kg })\end{array}$ & $\begin{array}{l}\text { Sodium } \\
(\text { mmolll) }\end{array}$ & $\begin{array}{l}\text { Chloride } \\
(\text { mmolll) }\end{array}$ \\
\hline $\mathrm{A}$ & 29 & $\Delta \mathrm{F} 508 / \mathrm{R} 117 \mathrm{H}$ & 75 & 176 & 56 & 54 \\
$\mathrm{~B}$ & 8 & $\Delta \mathrm{F} 508 / ?$ & 67 & 157 & 36 & 46 \\
$\mathrm{C}$ & 92 & $\Delta \mathrm{F} 508 / ?$ & 88 & 188 & 66 & 69 \\
$\mathrm{D}$ & 9 & $\Delta \mathrm{F} 508 / ?$ & 84 & 193 & 51 & 64 \\
\hline
\end{tabular}

\section{Results}

Table 2 presents the results obtained from the four measurements on sweat specimens of both $\mathrm{CF}$ and control subjects. The data show that there are ranges of overlapping values observed for some $\mathrm{CF}$ and control subjects and that this occurs for both direct and indirect measurements (albeit with varying degrees of magnitude). In the diagnostic setting, these limits of overlap would constitute the observed equivocal ranges, and included in table 2 are the numbers of subjects of both categories, with individual patients designated $\mathrm{A}$ to $\mathrm{N}$, whose values for each of the four measurements encompass the overlapping (equivocal) ranges.

From the data it appears that sweat conductivity and chloride measurements provide better discrimination between patient and controls than sodium and osmolality, with fewer data points overlapping within ranges of narrower limits. Only one of the CF patients (patient B) contributed "equivocal" values for all four measurements, the remaining three patients (A, C, and D) contributing to only those of sodium. The results obtained for the control subjects were similar, with only two (E and $\mathrm{G}$ ) providing "equivocal" values from each of three measurements, the remaining subjects contributing only to those of sodium and osmolality. Table 3 presents the individual results obtained for the four CF patients (A-D).

All four patients possessed one copy of the CFTR mutation $\triangle F 508$, and in one patient (A) $\mathrm{R} 117 \mathrm{H}$ was identified as the mutation on the other chromosome. In spite of extensive testing the second mutation could not be identified in the three other CF patients. At the time these sweat tests were performed all four patients had developed clear signs and symptoms of the disease; all had increased blood immunoreactive trypsin (IRT) concentrations at birth.

It was observed that among the control subjects, whose sweat test results overlapped those of CF patients, there was an apparent over representation of the relatively few older children (age $9-15$ years), $30 \%$ versus $7 \%$ in the entire control population. Although there were too few subjects to establish reference values within narrowly defined age ranges, the increase in sweat electrolyte which occurs with age whether measured by direct or indirect methods is clearly discernible (see table 4). No such age related effect could be shown in the CF patients (data not shown). When taking age into account, in respect of non-CF control reference values, the number of subjects exhibit- 
Table 4 Electrolyte measurements in subjects according to age

\begin{tabular}{|c|c|c|c|c|c|c|}
\hline $\begin{array}{l}\text { Age range } \\
\text { (mth) }\end{array}$ & No. subjects & & $\begin{array}{l}\text { Conductivity (mmol } \\
(\mathrm{NaCl} \mathrm{eq)/l)}\end{array}$ & $\begin{array}{l}\text { Osmolality } \\
\text { (mmol/kg) }\end{array}$ & $\begin{array}{l}\text { Sodium } \\
\text { (mmolll) }\end{array}$ & $\begin{array}{l}\text { Chloride } \\
\text { (mmol/l) }\end{array}$ \\
\hline \multirow[t]{3}{*}{$0.5-6$} & 43 & Control mean (SD) & $35(10)$ & $98(10)$ & $18(8)$ & $12(8)$ \\
\hline & & Observed range & $18-71$ & $67-169$ & $4-34$ & $3-47$ \\
\hline & & Range; control $\max _{\max }-\mathrm{CF}_{\min }$ & $71-100$ & $169-193$ & $34-75$ & $47-65$ \\
\hline \multirow[t]{3}{*}{$7-24$} & 50 & Control mean (SD) & $32(7)$ & $90(20)$ & $18(8)$ & $12(5)$ \\
\hline & & Observed range & $19-53$ & $65-158$ & $7-42$ & $6-25$ \\
\hline & & Range; control $1_{\max }-\mathrm{CF}_{\min }$ & $53-67$ & $158-157^{\star}$ & $42-36 \dagger$ & $25-46$ \\
\hline \multirow[t]{3}{*}{$25-108$} & 50 & Control mean (SD) & $39(10)$ & $106(24)$ & $27(10)$ & $15(7)$ \\
\hline & & Observed range & $20-55$ & $62-159$ & $9-51$ & $5-30$ \\
\hline & & Range; control $-\mathrm{CF}_{\text {in }}$ & $55-75$ & $159-176$ & $51-56$ & $30-54$ \\
\hline \multirow[t]{3}{*}{$108-177$} & 11 & Control mean (SD) & $52(9)$ & $137(19)$ & $44(10)$ & $24(11)$ \\
\hline & & Observed range & $35-67$ & $114-172$ & $36-66$ & $16-42$ \\
\hline & & Range; control ${ }_{\max }-\mathrm{CF}_{\min }$ & $67-101$ & $172-214$ & $66-73$ & $42-73$ \\
\hline
\end{tabular}

*Inverse range indicates equivocal cases. Cases contributing: CF case B; control case $\mathrm{H}$

†Inverse range indicates equivocal cases. Cases contributing: CF case B; control cases N, J, H.

Table 5 Sweat osmolality and sodium measurement in neonates

\begin{tabular}{llll}
\hline & & $\begin{array}{l}\text { Osmolality } \\
(\text { mmol/kg) }\end{array}$ & $\begin{array}{l}\text { Sodium } \\
(\text { mmol/l) }\end{array}$ \\
\hline $\mathrm{CF}$ & Mean (SD) & $241(20)$ & $91(14)$ \\
& Observed range & $196-289$ & $53-125$ \\
Control & $\mathrm{n}$ & 75 & 75 \\
& Mean (SD) & $103(24)$ & $22(11)$ \\
& Observed range & $66-173$ & $6-73$ \\
& $\mathrm{n}$ & 95 & 95 \\
\hline
\end{tabular}

ing equivocal results were now confined to those obtained by osmolality and sodium measurement, contributed by one $\mathrm{CF}$ and one control subject for osmolality, and one $\mathrm{CF}$ and three control subjects for sodium (table 4 ).

Sweat osmolality and sodium were measured in $75 \mathrm{CF}$ infants aged $2-12$ weeks (mean age 5.5 weeks) and in 95 control infants of the same age range (mean age 6.7 weeks). Sweat osmolality measurements discriminated between affected and non-affected infants whereas sodium did not (table 5).

\section{Discussion}

On theoretical grounds osmolality and conductivity measurement might be expected to provide very good discrimination between normal and CF sweat electrolyte concentrations. Sodium, potassium, and chloride, the predominant electrolyte constituents of sweat, are all increased in CF and the incremental contribution of each would be additive by virtue of the colligative nature of the measurement. On the other hand the contribution by other solutes and electrolytes present in sweat, in variable concentration and not specifically increased in $\mathrm{CF}^{7}$ would predictably diminish the discriminating power of these indirect measurements. The assumption that the latter, non-specific elements, predominate must underlie the assertion that only direct measurements of chloride can provide analytical results of diagnostic value. Support for that assumption is not to be found in the data presented here which suggests that, for all practical purposes, sweat conductivity measurement is as effective as chloride in distinguishing between $\mathrm{CF}$ and non-CF subjects.

Confidence intervals for differences between observed and expected proportions cannot be estimated because this population generates too few equivocal results: for conductivity measurement 1:57 CF, 2:154 non-CF; for chloride measurement 1:57 CF, 1:154 non-CF (table 2). Any generalisation about the practical implications of these findings must depend primarily on the assumption that the CF population sample studied was representative of patients presenting in routine clinical practice. Scrutiny of the data published by others, ${ }^{568}$ in both prospective and retrospective studies, shows that the proportion of cases and the range of values where $\mathrm{CF}$ and non-CF sweat test results overlap, obtained either by direct or indirect sweat electrolyte measurement, is very similar to the results we report here. For example, in two comparative case studies, the range of values for sweat conductivity, ${ }^{6}$ chloride, sodium, and osmolality ${ }^{5}$ obtained from "equivocal" cases have been cited as $51-79$ $\mathrm{mmol}(\mathrm{NaCl}$ eq) $/ 1, \quad 50-70 \mathrm{mmol} / \mathrm{l}, \quad 50-70$ $\mathrm{mmol} / \mathrm{l}$, and $150-200 \mathrm{mmol} / \mathrm{kg}$ respectively. For the latter three measurements the results obtained from all four of our "equivocal" CF cases (table 3) fell within or marginally below these values; but for conductivity, two cases (C and $\mathrm{D})$ had values greater than $80 \mathrm{mmol}(\mathrm{NaCl}$ eq) $/ 1$, which were predictive of CF. If, however, values for sweat chloride of greater than 60 $\mathrm{mmol} / 1$ are considered predictive of CF then the status of both these patients would be concordantly judged by both sweat chloride and conductivity measurement.

A recent survey ${ }^{9}$ has shown that the CF case yield, from sweat testing undertaken in laboratories serving major paediatric centres, is approximately one in 30 tests performed, from an annual (median) workload of 150 tests. On the basis of our findings, therefore, where sweat test results by either chloride or conductivity measurement are indistinguishable from "normal" in only one of $57 \mathrm{CF}$ patients, such a case would be expected to occur in clinical practice once in approximately 11 years. In fact such cases might occur even more rarely in the district general hospital laboratory/paediatric practice environment because the prediction of sweat test outcome ${ }^{9}$ has been based on a survey of experience gained in "specialist" laboratories which are likely to have more difficult cases referred to them for diagnostic or confirmatory sweat testing - that is, the case yield may be artificially inflated.

The results of sweat osmolality and sodium measurement are clearly less discriminatory than that of chloride or conductivity (table 2), in spite of the fact that both patient and control subjects in our study spanned a much narrower 
age range when compared with the subjects in other relevant studies. ${ }^{568}$ Our data show that a notable improvement in discriminatory power of the sweat test results, obtained either by direct or indirect measurement of electrolyte, occurs when the age of the subject is taken into account (table 4). Although age related changes in sweat electrolyte concentration have been recognised for some time ${ }^{45}{ }^{10}$ little attention seems to be given to this fact, and its potential for influencing the interpretation of a sweat result outside the traditional, but vague, concept of a demarcation between childhood and adulthood. ${ }^{21}$

The results we have obtained in infants under 12 weeks of age (table 5), show that a precisely defined reference range enables osmometry to be used with diagnostic sensitivity and specificity. Our data also suggest that for older children, refining the reference ranges with respect to age can considerably improve the diagnostic efficiency of sweat osmolality measurement (table 4). Despite this improvement overall sweat osmolality and sodium measurements remain marginally inferior to conductivity and chloride.

The only CF patient (case B) whose sweat test results, for osmolality and sodium, remained equivocal, when age was taken into account, is of particular interest. He presented at a few weeks of age with respiratory symptoms that were immediately suggestive of CF. His sweat test, for chloride, was diagnostically inconclusive when performed in a specialist $\mathrm{CF}$ centre and the diagnosis was established by nasal epithelium chloride channel conductance measurement. Although born outside East Anglia where his neonatal biochemical screen test did not include IRT measurement, at the age of 8 months retrospective testing of his neonatal dried blood specimen showed increased IRT concentrations characteristic of an infant with CF. At the same time we carried out the four parameter sweat test; the results obtained were less equivocal for conductivity than they were for chloride (table 3). Another of the four CF patients detected by newborn screening (case A, table 3), repeatedly had unequivocally normal sweat chloride concentrations when tested elsewhere as an asymptomatic neonate.

There were no outstanding clinical features which served to distinguish control subjects (N, J, H; table 4) whose sweat test results, when age was taken into account, remained equivocal. However, one of the control subjects (subject $G$ ) included in the four parameter sweat test study deserves special note (table 2). $\mathrm{He}$ was 1 month old when reviewed clinically for a positive neonatal screening test result; he was a well thriving infant with no discernible signs or symptoms of CF. He was found to be heterozygous for $\Delta \mathrm{F} 508$. His sweat test results were: conductivity $71 \mathrm{mmol}(\mathrm{NaCl}$ eq)/1, osmolality $169 \mathrm{mmol} / \mathrm{kg}$, sodium $33 \mathrm{mmol} / \mathrm{l}$, and chloride $47 \mathrm{mmol} / \mathrm{l}$. On the grounds that none of these results were diagnostic of CF he was considered not to be affected. However, with the exception of sweat sodium, all of these results were three to five standard deviations greater than the control mean for his age (table 4). With hindsight, and in the light of the cumulative findings from this study, it seems reasonably likely that control patient $\mathrm{G}$ might be affected with a mild CF genotype with the probability that the clinical phenotype will develop later. Although it is well known that a mild biochemical phenotype can be expressed in some heterozygotes for $\Delta \mathrm{F} 508,{ }^{12}{ }^{13}$ and probably for other "severe" mutations, the magnitude of the deviation from "normal" observed in the sweat electrolyte concentrations of subject $\mathrm{G}$ makes it unlikely that he is merely heterozygous for the one mutation detected. Should his status need redefining in the event of clinical manifestation of $\mathrm{CF}$, the inclusion of his sweat test results in the CF category would not alter the conclusions that we draw from this study.

At the present time it seems that CFTR mutation analysis is unlikely to provide the means whereby many of these "diagnostically equivocal" problems can be speedily resolved. Although all of our four cases (table 3) possessed the CFTR mutation $\Delta F 508$, in three of them (cases B, C, and D) the mutation on the other chromosome remained unidentified after tests which would have identified more than $90 \%$ of the CF mutations expected in our population. We anticipate that these three cases, like the fourth (case A, genotype, $\Delta \mathrm{F} 508 / \mathrm{R} 117 \mathrm{H}$ ), will possess one of the relatively rare "mild" mutations which, being dominant, will express as a mildly dysfunctional CFTR phenotype in the ductal epithelia of the sweat gland and probably in other tissues $^{14}$; in fact all four cases were pancreatic sufficient at the time of these sweat tests.

Indirect, physical chemical, measurement of sweat electrolytes, as described here, requires that the sample is collected directly as liquid from the iontophoresis site, in contrast with the absorbed sweat sampling technique as described by Gibson and Cooke $^{15}$ for direct sodium and chloride measurement. Although the Macroduct collection coil greatly reduces the risks of specimen evaporation and contamination, ${ }^{46}$ and osmolality and conductivity measurement virtually eliminate the potential for volumetric and gravimetric error inherent in the Gibson-Cooke procedure, some investigators ${ }^{6}$ have reported an unacceptable failure rate in obtaining a sufficient amount of sweat for analysis compared with the traditional sweat absorption pad method. We have no comparison to offer but the $1.4 \%$ failure rate we experienced in this population sample is perfectly acceptable by any criteria. Furthermore, using the Macroduct collection system over a period of many years, during confirmatory sweat testing for positive neonatal screening test results, we have failed to obtain sufficient sweat for accurate analysis at first attempt in only one infant; he was in postoperative intensive care following gastrointestinal surgery.

Our findings and experience lead us to conclude that, in the absence of conflicting comparative data, there is no rational basis for the strongly held view, emanating from clinical 
and laboratory practice in the USA, that indirect methods for the measurement of electrolytes are not as reliable as the traditional chemical analysis of chloride and sodium in the diagnosis of cystic fibrosis. We hope that the data presented here, and particularly that relating to sweat conductivity, will enable paediatricians and clinical biochemists to make an evidence based judgement about the scientific and clinical validity of the sweat test methods they choose to use in their practice. Clinical laboratories in the UK should welcome and benefit from current initiatives ${ }^{9}$ aimed at developing robust external quality assessment for all aspects of this important test.

We express our thanks to paediatrician and CF nurse specialis colleagues in East Anglia for their help in arranging the patient sweat tests, to Tony Mulville of CSP, Hornchurch, Essex for loan of a Wescor 5200 Osmometer and the supply of Macroducts for the study, and to Ms Dawn Anderson for the preparation of this manuscript.

1 Rosenstein BJ, Cutting GR. The diagnosis of cystic fibrosis: a consensus statement. F Pediatr 1998;132:589-95.

2 LeGrys VA, Burritt MF, Gibson LE, Hammond KB, Kraft K, Rosenstein BJ. Sweat testing: sample collection and quantitative analysis; approved guideline. National Committee for tative al 14(22) NCCLS, Villanova, Pennsylvania 19085, USA.

3 LeGrys VA. Sweat testing for the diagnosis of cystic fibrosis: practical considerations. F Pediatr 1996;129:892-7.
4 Carter EP, Barrett AD, Heeley AF, Kuzemko JA. Improved sweat test method for the diagnosis of cystic fibrosis. Arch Dis Child 1984;59:919-22.

5 Kirk JM, Keston M, McIntosh I, Al Essa S. Variation of sweat sodium and chloride with age in cystic fibrosis and normal populations: further investigations in equivocal cases. Ann Clin Biochem 1992;29:145-52.

6 Hammod KB, Turcios NL, Gibson LE. Clinical evaluation of the macroduct sweat collection system and conductivity analyzer in the diagnosis of cystic fibrosis. 7 Pediatr 1994;124:255-60.

7 Natelson S, Natelson EA. The sweat gland. In: Principles of applied clinical chemistry, Vol. 1, Maintenance of fluid and electrolyte balance. New York: Plenum Press, 1975.

8 Green A, Dodds P, Pennock C. A study of sweat sodium and chloride, criteria for the diagnosis of cystic fibrosis. Ann Clin Biochem 1985;22:171-6.

9 Kirk JM. A workshop organised by UK NEQAS Paediatric Specialist Advisory Group - report. Association of Clinical Biochemists (ACB) News 1998:427.

10 Hall SK, Stableforth DE, Green A. Sweat sodium and chloride concentrations - essential criteria for the diagnosis of cystic fibrosis in adults. Ann Clin Biochem 1990;27:318-20.

11 David TJ. Personal practise - cystic fibrosis. Arch Dis Child 1990,65:152-7.

12 Larouche D, Travert G. Abnormal frequency of $\Delta$ F508 mutation in transitory hypertrypsinaemia. Lancet 1991;1: 55.

13 Farrell PM, Koscik RE. Sweat chloride concentrations in infants homozygous or heterozygous for $\mathrm{F}_{508}$ cystic fibrosis. infants homozygous or he

14 Wilschanski M, Zielenski J, Markiewicz D, Tsui L-C, Corey M, Levison H, Durie PR. Correlation of sweat chloride concentration with classes of the cystic fibrosis transmembrane conductase regulator gene mutations. F Pediatr 1995; 127:705-10

15 Gibson LE, Cooke RE. A test for concentrations of electrolytes in sweat in cystic fibrosis of the pancreas utilising pilocarpine by iontophoresis. Pediatrics 1959;23:545-9. 